\title{
Immunoexpression of TTF-1 and Ki-67 in a coexistent anaplastic and follicular thyroid cancer with rare long-life surviving
}

\author{
El Ali Ziad', Marek Ruchala², Jan Breborowicz ${ }^{3}$, Maciej Gembicki², \\ Jerzy Sowinski², Marian Grzymislawski ${ }^{1}$
}

Departments of: ${ }^{1}$ Internal Diseases, Metabolic Disorders and Dietetics, ${ }^{2}$ Endocrinology and Metabolism, ${ }^{3}$ Tumours Pathology in the Chair of Oncology, University of Medical Sciences in Poznan, Poland

\begin{abstract}
We report the immunohistochemical diagnosis, including TTF-1 (thyroid transcription factor 1) and Ki-67, of a rare mixed thyroid neoplasm composed of minimally invasive well differentiated follicular areas and highly aggressive undifferentiated anaplastic areas. A 75 old female presented to our clinic with a rapidly growing neck mass. Considering the dynamics of the disease and the multiple challenges presented by the patient: advanced age, tumor size, history of a longstanding goiter we decided to transfer her to the department of surgery. The intraoperative findings were an enlarged right lobe with tracheal and surrounding tissues infiltration. Total thyroidectomy, radical neck lymph nodes dissection and tracheostomy were performed. The histopathological and immunohistochemical examination revealed a coexistent anaplastic and follicular thyroid carcinoma. The proliferation index Ki-67, a cell proliferation marker, was found to be significantly higher in the anaplastic areas $(30 \pm 5 \%)$ in the comparison with the follicular areas $(2 \pm 1 \%)$. The evaluation of the thyroid transcription factor 1 (TTF-1) expression revealed a correlation with the tumor cells aggressiveness accordingly to the cancer areas. After a radical surgery an external adjuvant radiation was applied. The patient is alive and more than five years after diagnosis she presented an increase of the serum thyroglobulin level suggesting, probably, a recurrence of the follicular form of the cancer. According to our survey we suggest that in thyroid cancers TTF-1 and Ki-67 could provides useful information on the differentiation activities of thyroid tumor cells and may be helpful to distinguish well differentiated and undifferentiated areas in a mixed thyroid cancer.
\end{abstract}

Key words: anaplastic thyroid cancer, follicular thyroid cancer, long survival, TTF-1, Ki-67

\section{Introduction}

The thyroid transcription factor 1 (TTF-1) is a protein belonging to the homeobox-containing gene family. This kind of protein plays very important roles in development, cell growth and differentiation processes [1]. TTF-1 is required for expression of the thyroid stimulating hormone receptor gene in thyroid cells and essential for the morphogenesis of the thyroid, lung and ventral forebrain [2].

One of the most important factors evaluating the biological aggressiveness of carcinoma is the cell proliferating activity. The presence of Ki-67, a nuclear protein expressed in all human proliferating cells

Correspondence: El Ali Z. Dept. of Internal Diseases, Metabolic Disorders and Dietetics, University of Medical Sciences, Przybyszewskiego Str. 49, 60-355 Poznan, Poland; tel.: (+4861) 8691330, fax.: (+4861) 8691682,

e-mail: zio73@poczta.fm except when they are at the $\mathrm{G}_{0}$ phase, has not been well studied in thyroid cancers. Anaplastic thyroid cancer (ATC) is a highly aggressive neoplasm and surgery is often not possible due to the involvement of vital structures in the neck. The survival of patients with ATC tends to be a matter of months, despite aggressive use of various therapeutic modalities.

The anaplastic transformation, or the intratumoral evolution of anaplastic carcinoma from pre-existing well differentiated thyroid cancer (WDC) has been described in several publications $[3,4]$. The possibility that well differentiated thyroid carcinoma can evolve into anaplastic thyroid carcinomas has particular importance in the prognosis and therapeutic approach to the management of thyroid neoplasm. In the presented report we intend to demonstrate the purposefulness of TTF-1 and Ki-67 immunocytochemical marker application as helpful in diagnosis and discrimination of the two different types of thyroid carcinomas. 


\section{Material and methods}

Patients. A 74 year old female, with a history of non-functioning long-standing thyroid goiter diagnosed approximately 20 years before, was admitted to the Department of Endocrinology and Metabolism in Poznan on May 2001 with a rapidly growing neck mass, that had gradually enlarged over the previous three months. The physical examination revealed a diffusely enlarged right thyroid lobe with palpable nodules. Thyroid function tests gave normal results. Ultrasonography of the neck revealed an enlarged right lobe with a volume of $53 \mathrm{ml}$. It contained multiple nodules with a dominant hypoechoic irregular nodule of $4.5 \mathrm{~cm}$ diameter. The left thyroid lobe had a volume of $6 \mathrm{ml}$. There were four enlarged $(1-1.4 \mathrm{~cm})$ cervical lymph nodes on the right side and no detectable lymph nodes on the left side. Trachea X-ray showed the trachea displaced to the patients left side. Chest X-ray was negative for metastatic disease. Fine needle aspiration biopsy was performed and the cytological examination revealed colloidal nodule of the thyroid with no signs of any malignancy. On June 2001 the patient was taken to the surgery for a thyroidectomy. The intraoperative findings were an enlarged right lobe with tracheal and surrounding tissues infiltration and enlarged cervical lymph nodes. Total thyroidectomy, radical neck lymph nodes dissection and tracheostomy were performed. Pathology report confirmed the diagnosis of ATC. Two cervical lymph nodes were removed with no cancer cells within. The patient recovered from her surgery and was referred to our Department for consideration of further therapy. On admission, serum thyrotropin (TSH) level was $13.5 \mu \mathrm{U} / \mathrm{ml}$ (normal 0.20-4.2), serum thyroglobulin ((Tg) level was $56.5 \mathrm{ng} / \mathrm{ml}$ (normal 0-70 ng/ml) and serum calcitonin level was undetectable (normal $0-10 \mathrm{pg} / \mathrm{ml}$ ). Chest and abdominal CT scan showed no signs of distant metastasis. Fiberoptic examination revealed a paralyzed right vocal cord. The histopathologic examination, verified at our institution, revealed a coexistence of anaplastic and follicular thyroid cancer (Fig. 1A).

The decision was made to treat the patient with adjuvant external radiotherapy, then she received a total dose of 51Gy. Acute toxicities included pharyngoesophagitis, but no chronic toxicity was observed. She completed therapy on July 2001. Thyroid function tests measured three months later, on levothyroxine (L-T4) substitution therapy, were in the euthyroid range with TSH level of 0.57 $\mathrm{mU} / \mathrm{l}$, serum Tg level was undetectable $(<3 \mathrm{ng} / \mathrm{ml})$. The neck ultrasonography disclosed no significant abnormality. Tracheostomy tube was removed on December 2002. The patient was followed up on L-T4 treatment regularly with physical exams, serum Tg and TSH levels, neck ultrasonography and chest X-ray. She continued to be in complete remission more than 4.6 years after diagnosis. On 2006 during a next follow-up visit serum Tg measured on L-T4 treatment was found to be elevated $(46 \mathrm{ng} / \mathrm{l})$. After one month of thyroxine withdrawal the patient was treated with $150 \mathrm{mCi}$ (millicuries) of 131-I. The 1-week-postablation whole body scan disclosed 131-I uptake in thyroid remnants. There was no pathological uptake outside the thyroid bed. A repeated thyroglobulin level under suppression was obtained three months later, it was $26 \mathrm{ng} / \mathrm{ml}$ suggesting a disease persistence. The patient is expected to be admitted to our Department for further therapy.

Immunohistochemical techniques. Immunohistochemical staining was performed on 4-6 $\mu \mathrm{m}$ thick paraffin-embedded sections according to the avidin-biotin-peroxidase method. Sections of paraffinembedded tissue samples were immunostained for TTF1, Ki67, thyroglobulin, leucocyte common antigen (LCA) and cytokeratin AE1/AE3 using monoclonal or polyclonal antibodies. The sections were incubated with the primary antibody in "antibody diluent" (DAKO) and goat anti-mouse or goat anti-rabbit EnVision-HRPenzyme conjugate was performed for 3 min each. The "highly sensitive 3,3' diaminobenzidine plus" (DAB+) chromogen (from DAKO) was used as substrate for the EnVision-HRP-enzymes. The slides were coumterstained with hematoxilin and eosin.

\section{Results}

Using mouse monoclonal anti-human antibodies we investigated the expression of the thyroid transcription factor 1 (TTF-1) in the follicular and anaplastic areas. The expression of TTF-1 was found to be positive in the nucleus of the follicular tumor cells (Fig. 1B) and negative effect was found in the nuclei of the anaplastic areas (Fig. 1C). Thyroglobulin expression was negative in the anaplastic areas contrary to the follicular areas (Fig. 1D,E). In order to eliminate non-Hodgkin's lymphomas staining for leucocyte common antigen, LCA (M070101, DAKO), was performed which was positive only in the blood derived cells (Fig. 1F). Using two second generation antibodies against proliferation marker, Ki-67 (N1633330, DAKO), we investigated the cells proliferative activity. The rate of tumor cells with nuclei positive for Ki-67 in the anaplastic areas was $30 \pm 5 \%$ and, moreover, among the Ki-67 positive cells a number of lymphocytes are seen as showing expression of the Ki-67 proliferation cell antigen (Fig. 1G). The diagnosis of the anaplastic thyroid carcinoma was also confirmed by immunohistochemically verified coexpression of mesenchymal vimentin (M072502, DAKO), and epithelial cytokeratin AE1/AE3 (M351501, DAKO) markers (Fig. 1H,I).

\section{Discussion}

ATC accounting $1.6 \%$ of all thyroid cancer is one of the most aggressive and lethal solid tumors known to affect humans. Very few anaplastic thyroid cancer patients survive longer than a year, and report of longterm survivors casts doubt on the validity of their diagnosis $[5,6]$. Passler and coworkers [7] found that irrespective of the surgical approach used, 5-year survival rate ranges from $4 \%$ to $8 \%$. It is essential to verify the diagnosis histologically and immunohistochemically because insular thyroid cancer, lymphomas, sarcomas, and medullary thyroid cancer are occasionally confused with anaplastic thyroid cancer. This is the first report of TTF-1 and Ki-67 expression investigated in a coexistent anaplastic and follicular thyroid cancer in a patient with rare long-life survival. Zhang and coworkers [8] investigated the expression of thyroid transcription factor 1 in thyroid neoplastic tissues in different degrees of differentiation and found that the localization of this transcription factor was gradually decreased corresponding to the progressive dedifferentiation of thyroid tumors. In our case we observed a positive expression of the TTF-1 in the follicular well differentiated areas and negative expression in the anaplastic undifferentiated (transformed?) areas, which is in agreement with the data published by other authors.

On the other hand, Katoh and coworkers [9] investigated the proliferation marker Ki-67 in thyroid neo- 

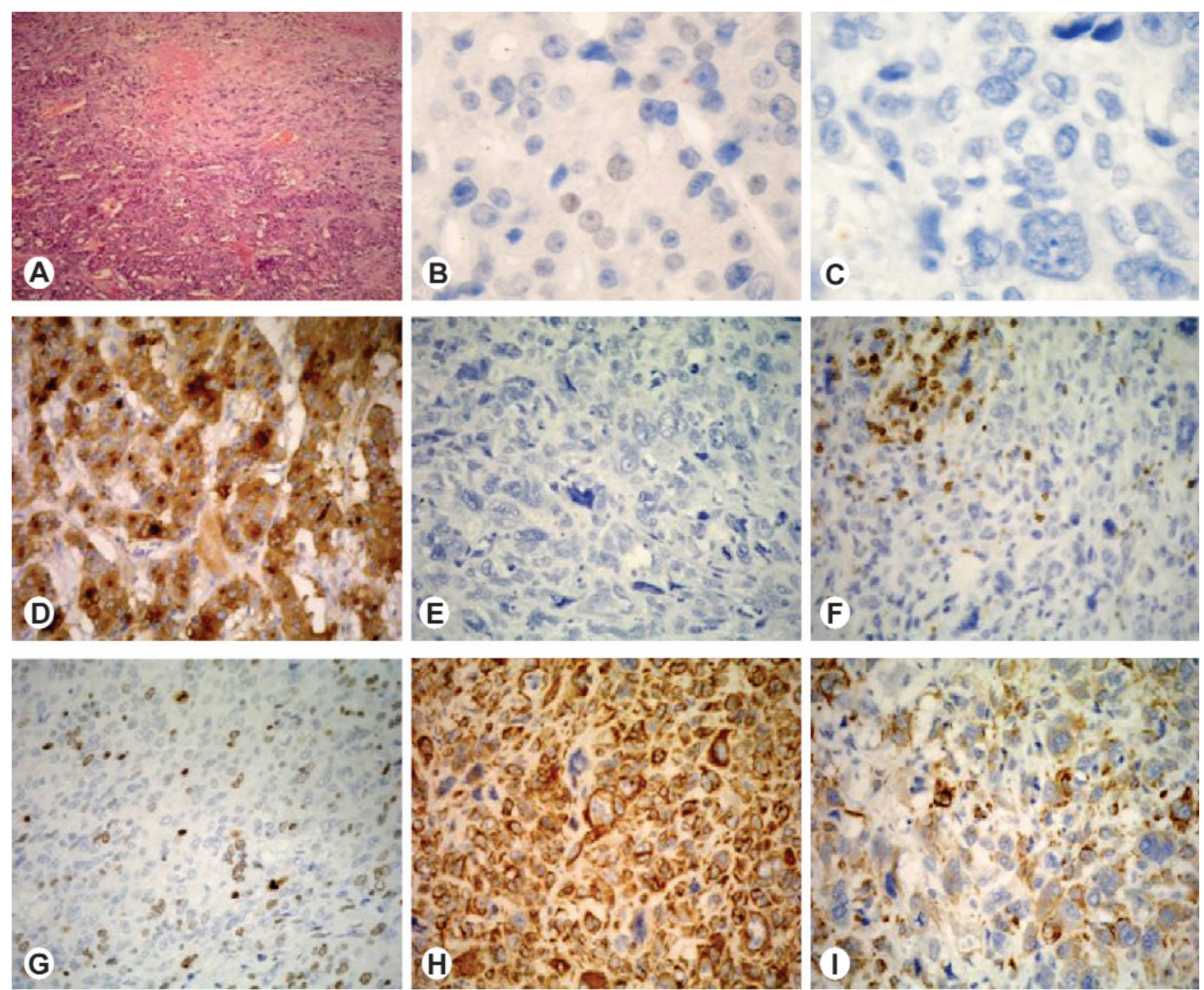

Fig. 1. Micrographs illustrating histology and the studied immunohistochemical markers in mixed follicular and anaplastic thyroid tumor. A. Staining with hematoxylin and eosin shows follicular cancer in the lower left corner and anaplastic type in the upper right corner (original magnification $\times 10$ ); B. immunohistochemical demonstration of TT1 expression in a number of cell nuclei of follicular cancer while no of the anaplastic cancer cells $(\mathbf{C})$ shows reaction for TT1 (original magnification $\times 40$ ); $\mathbf{D}$. follicular cancer cells showing positive reaction for thyreoglobulin but in the anaplastic area (E) the immunohistochemical reaction for the tyreoglobulin was negative (original magnification $\times 30$ ); F. in anaplastic area of tumor the LCA expression was limited to the blood derived cells and the reaction was lacking in anaplastic cancer cells (original magnification $\times 20$ ); G. marker of proliferating cells, Ki-67, was demonstrated immunohistochemically in the nuclei of both the anaplastic cancer cell and blood derived lymphocytes (original magnification $\times 2 \mathrm{x}$ ); $\mathbf{H}$. anaplastic cancer cells shows cytoplasmic expression of vimentin and (I) some cells of the anaplastic cancer showed expression of cytokeratins AE1/AE3 (original magnification $\times 30$ ).

plasms and showed that the highest ki-67 positive cell rate was seen in anaplastic thyroid carcinomas and it ranged between $12-70 \%$. In our case the $\mathrm{Ki}-67$ was 30 $\pm 5 \%$ in the anaplastic areas, while it does not exceed $2 \%$ in the follicular areas.

The coexistence of different histopathological types of thyroid cancer within the same neoplastic lesion is an unusual event. Wiseman et al. found that the coexistence of ATC with well differentiated cancer (WDC) ranged between $23 \%$ and $90 \%$, respectively [11]. These findings support the concept that many ATCs might arise from preexisting or coexisting WDC by malignant transformation [10-12]. In order to understand the anaplastic transformation recent studies have investigated the role of cell cycle regulators in thyroid carcinomas (p21, p27, p57), which are components of the Cip/Kip family. Tallini and coworkers [13] thoroughly analyzed 90 thyroid carcinomas of follicular cell origin and found that low p27 expression and high proliferative rate were associated with poor survival. Ito and coworkers [14] suggested that the downregulation of p57 protein is significantly related to the dedifferentiation of thyroid carcinoma and increasingly aggressive character of follicular carcinoma. Many 
authors have recently emphasized the role of the TP53 gene product, the $\mathrm{p} 53$ protein, in the anaplastic tumor development. Lam and others found that the loss of p53 or the presence of abnormal p53 can be responsible for transformation of WDC to ATC $[3,15]$. Stoler and coworkers [16] have noted that p53 alterations are rarely found in cell lines of WDC. There-expression of p53 in these cell lines has been shown to be associated with reversal of some aspects of the anaplastic transformation. These include restoration of chemosensitivity and radiosensitivity, inhibition of cellular proliferation, restoration of response to thyroid-stimulating hormone, and re-expression of thyroid peroxidase [16]. Because most of these data are gathered from anaplastic cell lines in vitro, they have to be interpreted with caution.

Finally, it is necessary to consider the infiltration of the anaplastic area by Ki-67 positive lymphocytes that has been demonstrated in this report. The blood derived cells showing expression of both, LCA and Ki67, we were able to recognize and document in anaplastic area of the tumor. A correlation of the inflammatory processes or infiltration by the cells showing both of the above mentioned markers in thyroid tumors and disease-free survival has been reported by Gupta and coworkers [17] especially, but not only, in children and young adults.

Summarizing our experience with this case and the effects of immunostaining it seems conceivable to suggest that in rapidly growing highly suspected thyroid masses the TTF-1 and Ki-67 could provides useful information on the differentiation step of thyroid tumor cells and may be helpful in discrimination between well differentiated and undifferentiated areas in a mixed thyroid tumor. Moreover, demonstration of the Ki-67 positive proliferating lymphocytes among the anaplastic tumor cells may indicate an interference of immune system into the tumor progression.

Acknoledgments: Supported in part by funds from Ministry of Science and Higher Education (grant 3951/P01/2006/31) to MR.

\section{References}

[ 1] Katoh R, Kawaoi A, Miyagi E, Li X, Suzuki K, Nakamura Y, Kakudo K. Thyroid Transcription Factor-1 in Normal, Hyperplastic, and Neoplastic Follicular Thyroid Cells Examined by Immunohistochemistry and Nonradioactive In Situ Hybridisation. Mod. Pathol. 2000;13:570-576.

[2] Lanzafame S, Caltabiano R, Puzzo L, Cappellani A. Thyroid transcription factor 1 (TTF1) and p63 expression in two primary thyroid papillary carcinomas of branchial cleft cysts. Virchows Arch. 2006;49:129-133.

[3] Wiseman SM, Loree TR, Hicks WL Jr, Rigual NR, Winston JS, Tan D, Anderson GR, Stoler DL. Anaplastic thyroid cancer evolved from papillary carcinoma: demonstration of anaplastic transformation utilizing the inter-simple sequence repeat polymerase chain reaction. Arch Otolaryngol Head Neck Surg. 2003;129:96-100.

[ 4] Hunt JL, Tometsko M, LiVolsi VA, Swalsky P, Finkelstein $\mathrm{SD}$, Barnes EL. Molecular evidence of anaplastic transformation in coexisting well-differentiated and anaplastic carcinomas of the thyroid. Am J Surg Pathol. 2003;27:1559-1564.

[5] Are C, Shaha A Anaplastic Thyroid Carcinoma: Biology, Pathogenesis, Prognostic Factors, and Treatment Approaches. Ann Surg Oncol. 2006;13:453-464.

[6] Wiseman SM, Loree TR, Rigual NR, Hicks WL Jr, Douglas WG, Anderson GR, Stoler DL: Anaplastic transformation of thyroid cancer: review of clinical, pathological, and molecular evidence provides new insights into disease biology and future therapy. Head Neck. 2003;25:662-670.

[ 7] Passler C, Scheuba C, Prager G, Kaserer K, Flores JA, Vierhapper H, Niederle B. Anaplastic (undifferentiated) thyroid carcinoma ATC). A retrospective analysis. Langenbeck's Arch Surg. 1999;384:284-293.

[ 8] Zhang P, Zuo H, Nakamura Y, Nakamura M, Wakasa T, Kadubo K Immunohistochemical analysis of thyroid-specific transcription factors in thyroid tumors. Path Int. 2006;56:240245.

[9] Katoh R, Bray CE, Suzuki K, Komiyama A, Hemmi A, Kawaoi A, Oyama T, Sugai T, Sasou S. Growth activity in hyperplastic and neoplastic human thyroid determined by an immunohistochemical staining procedure using monoclonal antibody MIB-1. Hum Pathol. 1995;26:139-156.

[10] Hunt JL, Tometsko M, LiVolsi VA, Swalsky P, Finkelstein $\mathrm{SD}$, Barnes EL. Molecular evidence of anaplastic transformation in coexisting well-differentiated and anaplastic carcinomas of the thyroid. Am J Surg Pathol. 2003;27:1559-1564.

[11] Wiseman SM, Loree TR, Hicks WL Jr, Rigual NR, Winston JS, Tan D, Anderson GR, Stoler DL. Anaplastic thyroid cancer evolved from papillary carcinoma :demonstration of anaplastic transformation utilizing the inter-simple sequence repeat polymerase chain reaction. Arch Otolaryngol Head Neck Surg. 2003;129:96-100.

[12] Galera-Davidson H, Bibbo M, Dytch HE, González-Cámpora R, Fernández A, Wied GL. Nuclear DNA in anaplastic thyroid carcinoma with a differentiated component. Histopathology. 1987; 11:715-722.

[13] Tallini G, Garcia-Rostan G, Herrero A, Zelterman D, Viale G, Bosari S, Carcangiu ML. Downregulation of p27kip1 and Ki67/Mib1 labeling Index Support the classification of Thyroid Carcinoma Into Prognostically Relevant Categories. Am J Surg Path. 1999;23:678-685.

[14] Ito Y, Yoshuda H, Nakano K, Ito Y, Yoshida H, Nakano K, Kobayashi K, Yokozawa T, Hirai K, Matsuzuka F, Matsuura N, Kuma K, Miyauchi A. Expression of p57/Kip2 protein in normal and neoplastic thyroid tissues. Int J Mol Med. 2002;9: 373-376.

[15] Lam, KL, Lo C, Chan K, Wan K. Insular and anaplastic carcinoma of the thyroid. A 45-year comparative study at a single institution and a review of the significance of p53 and p21. Ann Surg. 2000;231:439-338.

[16] Stoler DL, Datta RV, Charles MA, Block AW, Brenner BM, Sieczka EM, Hicks WL Jr, Loree TR, Anderson GR. Genomic instability measurement in the diagnosis of thyroid neoplasms. Head Neck. 2002;24:290-305.

[17] Gupta S, Patel A, Folstad A, Fenton C, Dinauuer CA, Tuttle RM, Contran R, Francis GL. Infiltration of differentiated thyroid carcinoma by proliferating lymphocytes is associated with improved disease-free survival for children and young adults. JCEM. 2001;86:1346-1354.

Submitted: 14 May, 2008 Accepted after reviews: 6 June, 2008 